\title{
Reconsideration of the Adsorption/Desorption Characteristics with the Influences of Water in Unconventional Gas Systems
}

\author{
Yunchao Pu $\mathbb{D}^{1},{ }^{1}$ Yanchun Wang ${ }^{D},{ }^{1}$ Juntai Shi $\mathbb{D}^{2}$ and Keliu Wu $\mathbb{D}^{2}$ \\ ${ }^{1}$ School of Geophysics and Information Technology, China University of Geosciences (Beijing), Beijing 100083, China \\ ${ }^{2}$ MOE Key Laboratory of Petroleum Engineering in China University of Petroleum at Beijing, Beijing 102249, China \\ Correspondence should be addressed to Yanchun Wang; w123yc@163.com
}

Received 9 May 2020; Revised 30 October 2020; Accepted 13 November 2020; Published 7 December 2020

Academic Editor: Jinze Xu

Copyright ( 2020 Yunchao Pu et al. This is an open access article distributed under the Creative Commons Attribution License, which permits unrestricted use, distribution, and reproduction in any medium, provided the original work is properly cited.

\begin{abstract}
The exploration and development of unconventional resources have been of growing interest in the industry in recent years. It is widely known that the adsorption and desorption mechanisms of unconventional gas have great significance for gas accumulation and exploration. However, major researches based on the mechanism of solid-gas interface have failed to reveal it completely, which introduce large discrepancies between actual and predicted production. In this paper, the mechanism of solid-liquid-gas adsorption and desorption interface is enlightened to describe the characteristics of unconventional gas. The validity of the proposal was verified preliminarily by building a conceptual model which redefines the gas-water distribution. Furthermore, the possibility of production of gas trapped in micropores was first investigated. The findings of this study can help for better understanding of the adsorption, desorption, and production mechanisms and in unconventional gas system. Accordingly, the explanation of variation between experiment result and actual production rate even with physical parameters was reasonable in theory. Therefore, this work should provide a basis for improving the accuracy of production predictions in actual reservoirs and should assist analysts in determining reasonable unconventional gas target.
\end{abstract}

\section{Introduction}

The worldwide boom in unconventional oil and gas, wellknown as unconventional energy resource revolution, has a significant impact on the balance of hydrocarbon production in the field of energy [1]. The abundant resources contained in gas-bearing shale and coalbed have received renewed attention as important unconventional natural gas resources with worldwide distribution [2-4], especially after a breakthrough made in the development of the Barnett Shale gas in 1997 [5-8] and followed by the development of the Haynesville, Marcellus, and Fayetteville shale gases $[9,10]$.

Unconventional natural gases are derived from the organic matter through biogenic or thermogenic processes [11-13]. Except that a small amount of gas occurs as dissolved gas in residual oil and water, the mutual recognition is that most of the gas occurs as adsorbed gas in organic mat- ters and clay minerals of unconventional natural gas system or as free gas in pores and fractures of the system [14-18]. The published reports showed that the composition ratio of adsorbed gas and free gas in the major shale gas-producing layers in North America varies substantially, and the range of adsorbed gas content through experiment studies is relatively wide, about $20-85 \%[19,20]$. With the deepening of research, scholars have a relatively clear understanding about the factors affecting unconventional gas adsorption capacity, including the physical and chemical properties of organic matter (abundance, type, maturity, mineral composition, water content, etc.) and external conditions (temperature, pressure, etc.) [21-23]. For instance, Chalmers and Bustin $[24,25]$ studied the methane adsorption capacity of a succession of sandstone, siltstone, shale, and coal from the Lower Cretaceous Fort St. John Group of Northeastern British Columbia and found a positive correlation between methane 
adsorption capacity of shale and organic matter content, micropore volume, and TOC content.

However, the exploration and development of unconventional gas reservoirs face great challenges [26, 27]. For example, adsorption and desorption mechanisms are important for the unconventional gas and are mainly studied through high-pressure experiments with methane [28, 29]. Studies for decades of unconventional gas reservoirs indicate the particularity and complexity of diagenesis and relationship between methane and formation water in the process of diffusion, adsorption, and accumulation in the pores, as well as the influence of water on drainage and depressurization production. Some scholars noticed that there are significant differences between the actual production and experimental results based on adsorption and desorption mechanisms of solid-gas interface, which is expressed by the Langmuir isotherms. Constantly promoted with technologies applied to researches, it has been widely acknowledged that the water has nonignorable impacts on adsorption and desorption characteristics as one of the important occurrences in all stages. For example, Ross and Bustin [30] concluded that the shale sample with a relatively high clay mineral content has a low gas adsorption capacity due to the high equilibrium water content, and the gas adsorption capacity of the shale sample does decrease with increasing humidity because some adsorption sites are occupied by water molecules [31, 32].

Although some scholars have analyzed the occurrence of water and the reason of variation between experiment result and actual production rate preliminarily, some details of the mechanisms are not well understood. Our previous experimental study [33] showed that there is no positive correlation between adsorption amount of methane and the pressure. Meanwhile, the characteristics of desorption are not sensitive to pressure. In this paper, the occurrence of water and initial water distribution in the system was presented comprehensively in the theory by analyzing the characteristics of water in shale and coalbed during reservoir forming process qualitatively and quantitatively. Accordingly, the mechanism of solid-liquid-gas interface is enlightened to describe the adsorption and desorption characteristics of unconventional gas. The validity of the proposal was verified preliminarily by building a conceptual model which redefines the gas-water distribution in the system of unconventional gas reservoirs and gives an insight into the process of gas adsorption and desorption. Furthermore, the possibility of desorption and production of gas trapped in micropores/mesopores was first investigated, which will directly affect potential unconventional reserves. Therefore, this work should provide a basis for improving the accuracy of production prediction and determining reasonable targets in actual unconventional gas reservoirs.

\section{Occurrence of Water and Initial Water Distribution in the System}

With the development of chemical analysis technologies, it has been widely acknowledged that the water not only is one of important occurrences in all stages but also has nonignorable impacts on adsorption and desorption characteris- tics of unconventional gas system. Meanwhile, the products generated during the formation and accumulation of unconventional gas reservoirs were quantitatively described by currently reported researches $[34,35]$. However, the characteristics and distribution of water within the system (e.g., organic-matter pore, cleat, matrix) are not demonstrated clearly. These issues are discussed in this section and summarized in Table 1 and Figure 1.

Researches on hydrocarbon generation processes in shale demonstrated that water is involved during each thermal evolution phase including pyrolysis and thermal cracking, which is reflected clearly in the composition analysis of hydrogen isotopes in the products $[35,36]$, (Helgeson et al. 2015). Moreover, studies on CBM showed that the water is formed in all stages of diagenetic metamorphism [37]. Extensive reports illuminated that water exists as a prominent factor in the process of formation and production, including the strong-water environment during peatification, the weakwater environment dominated by temperature and pressure, and the process of coalification and compression drainage.

As previously mentioned, the system of unconventional gas reservoir was in a continuous water environment, even though the intensity and period of gas generation varied in different sizes of organic macerals and different locations of reservoirs. In this work, a conceptual model of initial water distribution was built by integrating the results of theoretical and experimental researches for further study.

\section{Adsorption Mechanism in Aqueous Environment}

Researchers have a relatively clear understanding about the factors affecting unconventional gas adsorption capacity, but few reports have conducted in-depth analysis on the mechanism of gas adsorption from the perspective of gaswater distribution in the system. These issues are discussed in this section and summarized in Table 2 and Figure 2.

Adsorption, first known use as a scientific term in 1881, is adhesion in an extremely thin layer of molecules (as of gases, solutes, or liquids) to the surfaces of solid bodies or liquids with which they are in contact. With the development of modern physical chemistry and surface chemistry, it brought dawn to the improvement of adsorption theory. Take solidgas interface adsorption for example, the solid has a certain degree of adsorption to the gas due to the activity, roughness, incompleteness, and surface energy of the atoms on the surface. According to the properties of the force between the solid surface (adsorbent) and the gas (adsorbate), the adsorption of gas by solids is usually divided into physical adsorption and chemisorption.

Not only physical adsorption but also chemisorption occurs in the complex process of unconventional gas reservoir formation with changes of environment parameters according to adsorption theory. However, it is generally accepted that the mechanisms of gas adsorption are mainly studied through high-pressure methane adsorption experiments which were carried out with dry coal samples at early stage [38]. The result showed that it is a typical gas-phase adsorption in which the interaction only exists between the 
TABLE 1: Characteristics of water in shale and coalbed during reservoir forming process.

\begin{tabular}{|c|c|c|c|c|}
\hline \multirow[t]{2}{*}{ Sample } & \multicolumn{4}{|c|}{ Characterization parameters } \\
\hline & Coalification process & Participants & Production & Evaluation method \\
\hline \multirow{6}{*}{ Coalbed } & Biochemical coalification & $\begin{array}{l}\text { Organic matter, bacteria and fungi, } \\
\text { swamp water, oxygen }\end{array}$ & $\mathrm{H}_{2} \mathrm{O}, \mathrm{CH}_{4}, \mathrm{CO}_{2}$, and $\mathrm{N}_{2}$ & \multirow[t]{2}{*}{ Qualitative } \\
\hline & Geochemical coalification & Surface water, remains of plant and animal & Coal & \\
\hline & Rank & Participants & Production & \multirow[t]{2}{*}{ Evaluation method } \\
\hline & Lignite and bituminous & Plant (1 unit) & $\begin{array}{c}\mathrm{H}_{2} \mathrm{O} \text { (64 units), } \mathrm{CH}_{4} \text { (8 units) } \\
\text { and } \mathrm{CO}_{2} \text { (2 units) }\end{array}$ & \\
\hline & Semianthracite & Bituminous (1 unit) & $\begin{array}{c}\mathrm{H}_{2} \mathrm{O}(7.87 \text { units }), \mathrm{CH}_{4}(9.23 \text { units }), \\
\text { and } \mathrm{CO}_{2} \text { (3 units) }\end{array}$ & \multirow[t]{2}{*}{ Quantitative } \\
\hline & Anthracite & Semianthracite (1 unit) & $\mathrm{H}_{2} \mathrm{O}$ (1 unit) and $\mathrm{CH}_{4}$ (36 units) & \\
\hline \multirow{3}{*}{ Shale } & Rank & Participants & Production & Evaluation method \\
\hline & Pyrolysis & Bituminous (1 unit) & $\begin{array}{c}\mathrm{H}_{2} \mathrm{O} \text { (7.87 units), } \mathrm{CH}_{4} \text { (9.23 units), } \\
\text { and } \mathrm{CO}_{2} \text { (3 units) }\end{array}$ & \multirow[t]{2}{*}{ Qualitative } \\
\hline & Thermal cracking & Semianthracite (1 unit) & $\mathrm{H}_{2} \mathrm{O}$ (1 unit) and $\mathrm{CH}_{4}$ (36 units) & \\
\hline
\end{tabular}

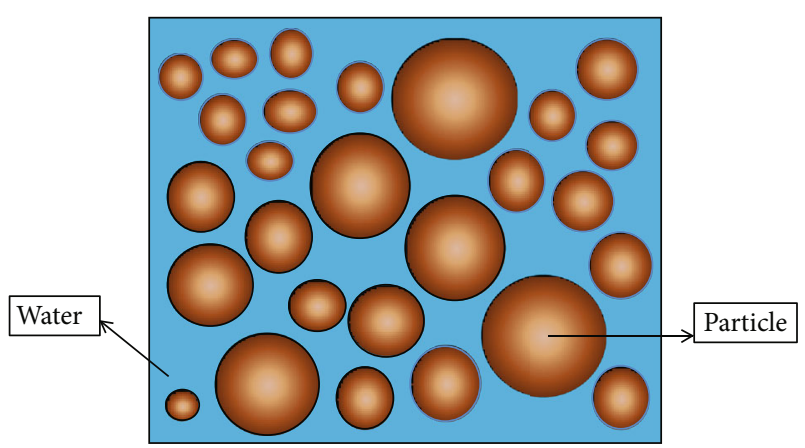

Figure 1: Distribution of water within unconventional gas system (conceptual model).

gaseous methane molecule and coal particles. According to the Langmuir module, the adsorption amount has a positive correlation with pressure. But there is limited practical significance using dry samples due to inconsideration of the reservoir conditions. Therefore, the experiments considering water content were commonly adopted to investigate effects of water on methane adsorption amounts. Ross and Bustin [30] studied the methane adsorption capacity of the organic-rich shale from the Lower Jurassic Gordondale Member and found that the moisture-equilibrated shale samples have lower gas adsorption capacity than the dry shale samples because water molecules occupy the adsorption sites. Meanwhile, some scholars have carried out a definite upper limit of moisture content for coal samples which has no further effects on methane adsorption. Although scholars have analyzed the gas adsorption considering the effects of water, some details are incomplete on the characteristic of water during methane generation and the interaction with methane during adsorption process.

In this paper, further studies were conducted based on the conceptual model mentioned above. When generated by organic matters, the methane is adsorbed on the internal surface of neighboring particles as a monolayer in an aqueous environment synchronously (Figure 2(a)). There is a competitive relationship between water and gas during adsorption process according to the principle of "similarity and intermiscibility." Then, surplus methane dissolves into water and diffuses to the peripheral region through the water flow driven by the concentration difference of methane, while multilayer adsorption occurs (Figure 2(b)). With the process of gas generation, the system will gradually reach saturation with dynamic balance of adsorption and dissolution. After that, the concentration of gas increases with further generation to exceed the equilibrium solubility and gas bubbles which normally attached to pore walls come into being (Figure 2(c)). The variation of volume and internal pressure in these bubbles can be described by state equation of gas. When the size of bubbles approach pore diameters by growing or coalescing, gas will get trapped in the pores [39] due to the high capillary force in the pore throats, especially in micropores. Therefore, the trapped gas, pore water, and organic particles constitute the three-phase equilibrium system of gas-water-solid (Figure 2(d)).

\section{Reconsideration of Desorption Mechanism of Unconventional Gas System}

It is generally believed by the scholars and engineers at early stage that the adsorption and desorption of unconventional gas are reversible processes which have laid a solid foundation of solid-gas interface mechanism. But there are essential differences (e.g., conditions, characteristics) between adsorption and desorption. These issues are discussed in this section and summarized in Tables 3 and 4 and Figure 3.

Due to slight temperature changes associated with chemical stability during drainage and depressurization production, we focus on the research of physical desorption. Compared with the long term and complexity of adsorption, the desorption process is relatively short and simple. The amount of desorption mainly depends on the amplitude and velocity of pressure drop along with pore conditions. 
TABLE 2: Comparison of physical adsorption and chemisorption.

\begin{tabular}{lcc}
\hline Characteristics & Physical adsorption & Chemisorption \\
\hline Adsorption force & Van der Waals' force & Chemical bond force \\
Adsorption heat & Approximation of heat of liquefaction & Approximation of chemical reaction heat \\
Adsorption temperature & Low (under critical temperature) & Fairly high (outclass boiling point) \\
Adsorption rate & Fast & Slow \\
Selectivities & No & Yes \\
Adsorbed layers & Monolayer or multilayer & Monolayer \\
Characteristics of desorption & Complete desorption & Difficulty with chemical reaction \\
\hline
\end{tabular}

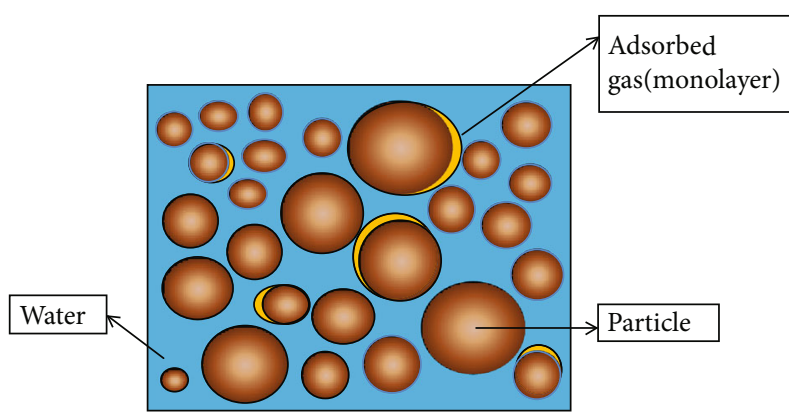

(a)

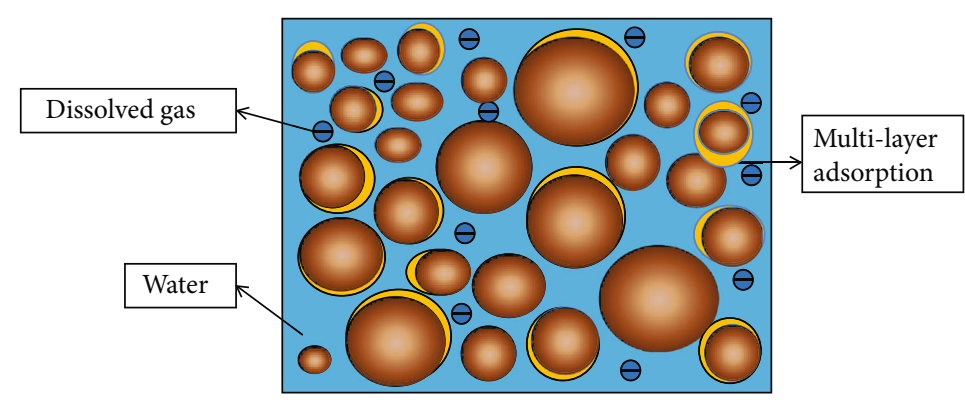

(b)

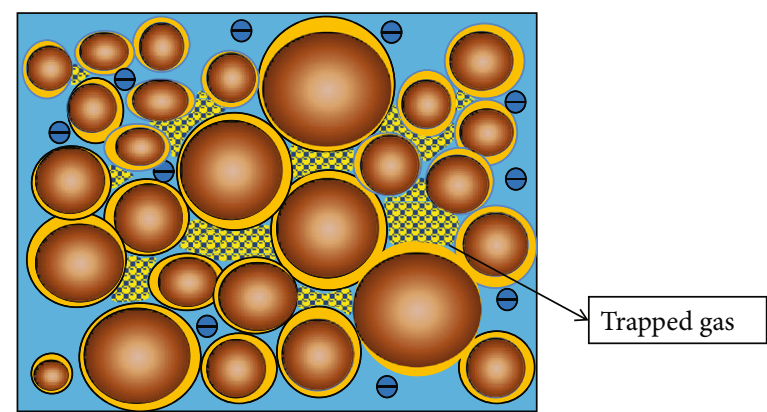

(d)

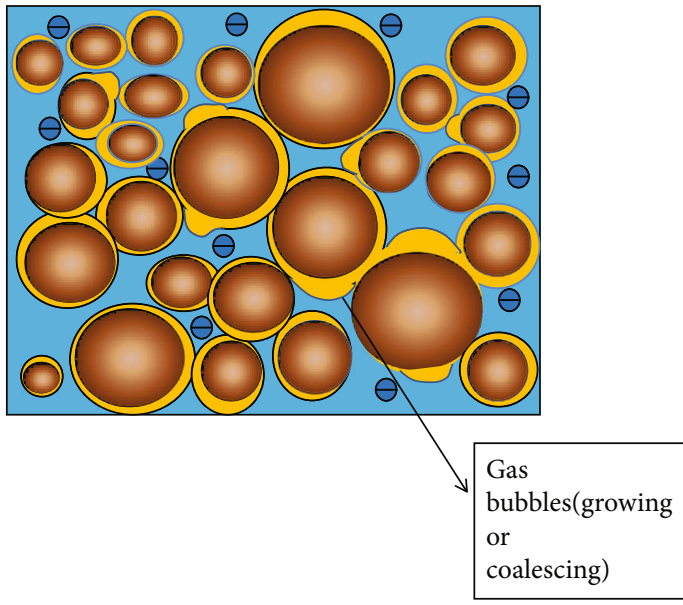

(c)

FIGURE 2: Accumulation process and adsorption characteristics of unconventional gas based on the conceptual model. 
TABLE 3: Comparison of the essential differences between physical adsorption and physical desorption.

\begin{tabular}{|c|c|c|}
\hline Characteristics & Physical adsorption & Physical desorption \\
\hline $\begin{array}{l}\text { The process of } \\
\text { action }\end{array}$ & $\begin{array}{l}\text { Coupled to the thermal evolution } \\
\text { of hydrocarbon generation and } \\
\text { expulsion process (spontaneously) }\end{array}$ & Drainage-depressurization-desorption (passively) \\
\hline Time & Long term (millions of years) & Quiet short (days or hours) \\
\hline Types & Physical adsorption and chemisorption & $\begin{array}{l}\text { Physical adsorption (including depressurized desorption, } \\
\text { dispersed desorption, displacement desorption, } \\
\text { and temperature rise desorption) }\end{array}$ \\
\hline Conditions & $\begin{array}{c}\text { Dehydration, rise of temperature, and pressurization } \\
\text { during the formation of gas reservoirs }\end{array}$ & $\begin{array}{l}\text { Limited pressure drop, restricted matrix pores, } \\
\text { and permanent temperature }\end{array}$ \\
\hline $\begin{array}{l}\text { Influence } \\
\text { factor }\end{array}$ & $\begin{array}{l}\text { Adsorptive capacity of gas-bearing organic matters, } \\
\text { pressure, temperature, and moisture content }\end{array}$ & Dispersion speed of free-state gas, etc. \\
\hline
\end{tabular}

TABLE 4: Analysis of experimental data.

\begin{tabular}{llcccc}
\hline \multirow{2}{*}{ Experiment/parameter } & & \multicolumn{2}{c}{ Pressure (MPa) } & \multirow{2}{*}{ Adsorption/desorption $\left(\mathrm{mol}^{*} \cdot \mathrm{kg}^{-1}\right)$} & \multirow{2}{*}{ Desorption $(\%)$} \\
\hline \multirow{2}{*}{ Experiment 1 (saturated water) } & Adsorption & 8.37 & 5.22 & 0.5801 \\
& Desorption & 5.22 & 1.08 & 0.0289 & 4.98 \\
Experiment 2 (saturated water) & Adsorption & 5.22 & 2.965 & 0.5248 & 0.0221 \\
& Desorption & 2.965 & 0.537 & 1.1313 & 4.21 \\
Experiment 3 (equilibrium water) & Adsorption & 9.13 & 5.36 & 0.3246 & 25.65 \\
& Desorption & 5.36 & 0.91 & & \\
\hline
\end{tabular}

Based on the differences in the process of action, condition, time, and types, a classification proposal of four subgroups was put forward [40]. The basic characteristic of depressurized desorption is described by the Langmuir module, which is one of the commonest types of desorption. Dispersed desorption is coupling interactions of desorption and diffusion due to gradient concentration difference between the pores and the matrix, which is an important type of desorption in unconventional gas system. The essence of displacement desorption is that the water or other gas molecules displace the position of adsorbed methane molecules to achieve dynamic equilibrium, which is a typical process of competitive adsorption of different components. The feasibility of $\mathrm{CO}_{2}$ displacement of methane had been theoretically verified and applied to production. Modern physicochemical studies show that the adsorption capacity of adsorbent on adsorbate is a function of adsorbate, properties of adsorbent and its interaction, pressure, and temperature, which is negatively correlated with adsorption capacity and positively correlated with desorption capacity. Consequently, temperature can be regarded as a driving force of desorption by increasing the ability to overcome the Van der Waals Force.

However, it is noteworthy that the desorption ratio is lower than previous experiment outcomes [33] which indicate that desorption amount is not sensitive to pressure in the three-phase dynamic equilibrium system of gas-watersolid. Distinguished from direct effects on the system of solid-gas, the pressure is working on the three-phase system indirectly. With the depressurization progress of production, the balance of both methane dissolution in pore water and the adsorption within the pores will be broken up caused by coupling of concentration and solubility (Figures 3(a) and 3(c) as schematic graph and Figures 3(b) and 3(d) as molecular simulation). On the one hand, there is a dynamic progress of equilibrium between methane dissolution and evolution in pore water during production. As the pressure decreases, supersaturation of methane occurs due to the positive correlation between the solubility and pressure, which is the resistance of desorption. This is a reasonable explanation for low critical pressure and hysteresis of desorption in reported experiments and actual production. On the other hand, there is the rebuilding of equilibrium between methane adsorption and desorption on the surface of pores. The concentration of methane in pore water decreases gradually with evolution of methane due to depressurization, which leads to desorption of methane.

The process and characteristics of desorption were simulated based on the conceptual model. Nucleation is the spontaneous process of the appearance of evolution gas, which tends to coalesce with free gas or undergo physallization at the boundary between water and solid (Figure 3(e)). Driven by further decrease of water pressure, the volume of gas bubbles expands to form the continuous phase and the gas-water interface migrates to the matrix and cleat for production gradually (Figure 3(g)). According to the Laplace-Young equation, the capillary resistance reaches the maximum at the throats of pores $(r)$. Moreover, free-gas pressure $\left(P_{\mathrm{g}}\right)$ within pores will be higher than water-phase pressure $\left(P_{\mathrm{w}}\right)$ at the boundary (Figures 3(f) and 3(h)). Gas bubbles can break through the throat by overcoming the capillary force 

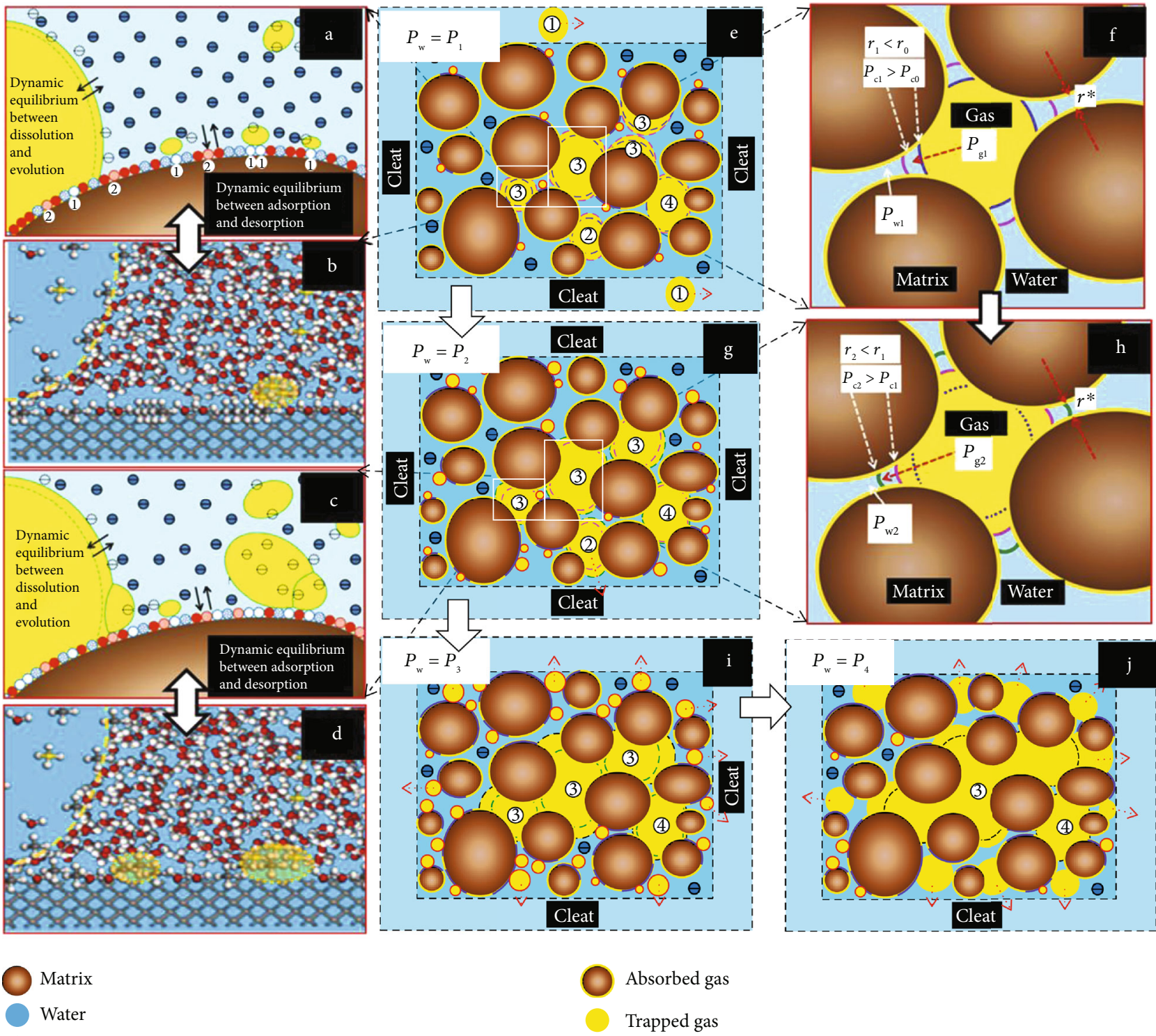

Figure 3: Process of drainage depressurization in the unconventional gas system.

$\left(P_{c}\right)$ with enough energy. However, a clear but unfortunate conclusion we reached is that the residual gas (e.g., part of absorbed gas, trapped gas bubbles in micropore due to capillary force) cannot be released, which has a significant impact on production even under abandonment pressure.

\section{Conclusions and Recommendations}

The mechanism of solid-liquid-gas adsorption and desorption interface has been applied to describe the characteristics of unconventional gas, which explained the variation between actual and predicted production reasonably. The following are the main conclusions from the study:

(1) During the formation, accumulation, adsorption, and desorption of unconventional gas reservoirs, water not only is one of important occurrences in all stages but also has nonignorable impacts on the system. Meanwhile, the characteristics and distribution of water within the system were investigated and a conceptual model was built considering initial water distribution

(2) An in-depth analysis from the perspective of gaswater distribution on the mechanism of adsorption of unconventional gas reservoirs was conducted, and a new approach was put forward to describe the process and characteristics of adsorption in the gas-water-solid equilibrium system

(3) The desorption characteristics based on the gas-watersolid equilibrium system in unconventional gas reservoirs were demonstrated, which are of great significance to further understand the mechanism. Furthermore, the residual gas, including part of absorbed gas and trapped gas bubbles in micropore, is the main reason 
for the differences of actual and predicting production. It could provide a scientific basis for the development of unconventional gas industry

Although the mechanism of solid-liquid-gas adsorption and desorption interface with a conceptual model considering gas-water distribution has been illustrated, the molecular simulation, modeling of fluid flow, and mass transport in porous media based on the gas-water-solid equilibrium system need to be further studied to provide a more comprehensive understanding of the mechanism and characteristics of adsorption, desorption, and production in the unconventional gas system. Meanwhile, the studies that focused on enhancement of residual-gas production should be paid more attention in the industry.

\section{Data Availability}

The experimental data that were used to support this study are shown in Table 4.

\section{Conflicts of Interest}

No conflicts of interest exist in the submission of this manuscript.

\section{Acknowledgments}

This work is sponsored by inversion methods study of sedimentary model constrained lithofacies and fluid identification (Grant No. P18075-6) and National Science and Technology Major Project of the Ministry of Science and Technology of China (Grant No. 2016ZX05003-003).

\section{References}

[1] EIA/ARI, World shale gas and shale oil resource assessment, Advanced Resources International, Inc, 2013.

[2] L. He, H. Mei, X. Hu, M. Dejam, Z. Kou, and M. Zhang, "Advanced flowing material balance to determine original gas in place of shale gas considering adsorption hysteresis," SPE Reservoir Evaluation \& Engineering, vol. 22, no. 4, pp. 1282-1292, 2019.

[3] M. Wei, Y. Duan, M. Dong, Q. Fang, and M. Dejam, "Transient production decline behavior analysis for a multifractured horizontal well with discrete fracture networks in shale gas reservoirs," Journal of Porous Media, vol. 22, no. 3, pp. 343-361, 2019.

[4] L. C. Zhang, B. Li, S. Jiang et al., "Heterogeneity characterization of the lower Silurian Longmaxi marine shale in the Pengshui area, South China," International Journal of Coal Geology, vol. 195, pp. 250-266, 2018.

[5] H. Bi, Z. X. Jiang, J. Z. Li, F. Y. Xiong, P. Li, and L. Chen, "Ono -Kondo model for supercritical shale gas storage: a case study of Silurian Longmaxi shale in southeast Chongqing, China," Energy \& Fuels, vol. 31, no. 3, pp. 2755-2764, 2017.

[6] K. A. Bowker, "Barnett shale gas production, Fort Worth Basin: issues and discussion," AAPG Bulletin, vol. 91, no. 4, pp. 523-533, 2007.

[7] D. M. Jarvie, R. J. Hill, T. E. Ruble, and R. M. Pollastro, "Unconventional shale-gas systems: the Mississippian Barnett
Shale of north-central Texas as one model for thermogenic shale-gas assessment," AAPG Bulletin, vol. 91, no. 4, pp. 475-499, 2007.

[8] S. L. Montgomery, D. M. Jarvie, K. A. Bowker, and R. M. Pollastro, "Mississippian Barnett Shale, Fort Worth basin, north-central Texas: gas-shale play with multi-trillion cubic foot potential," AAPG bulletin, vol. 89, no. 2, pp. 155-175, 2005.

[9] T. L. Guo, "Key geological issues and main controls on accumulation and enrichment of Chinese shale gas," Petroleum Exploration and Development, vol. 43, no. 3, pp. 349-359, 2016.

[10] J. Peischl, T. B. Ryerson, K. C. Aikin et al., "Quantifying atmospheric methane emissions from the Haynesville, Fayetteville, and northeastern Marcellus shale gas production regions," Journal of Geophysical Research - Atmospheres, vol. 120, no. 5, pp. 2119-2139, 2015.

[11] R. J. Hill, E. T. Zhang, B. J. Katz, and Y. C. Tang, "Modeling of gas generation from the Barnett Shale, Fort Worth Basin, Texas," AAPG Bulletin, vol. 91, no. 4, pp. 501-521, 2007.

[12] B. M. Krooss, R. Littke, B. Müller, J. Frielingsdorf, K. Schwochau, and E. F. Idiz, "Generation of nitrogen and methane from sedimentary organic matter: implications on the dynamics of natural gas accumulations," Chemical Geology, vol. 126, no. 3-4, pp. 291-318, 1995.

[13] H. Tian, L. Pan, X. M. Xiao, R. W. T. Wilkins, Z. P. Meng, and B. J. Huang, "A preliminary study on the pore characterization of Lower Silurian black shales in the Chuandong Thrust Fold Belt, southwestern China using low pressure $\mathrm{N}_{2}$ adsorption and FE-SEM methods," Marine and Petroleum Geology, vol. 48, pp. 8-19, 2013.

[14] L. Chen, Z. X. Jiang, K. Y. Liu, J. Q. Tan, F. L. Gao, and P. F. Wang, "Pore structure characterization for organic-rich Lower Silurian shale in the Upper Yangtze Platform, South China: a possible mechanism for pore development," Journal of Natural Gas Science and Engineering, vol. 46, pp. 1-15, 2017.

[15] L. Chen, Z. X. Jiang, K. Y. Liu et al., "Relationship between pore characteristics and occurrence state of shale gas: a case study of Lower Silurian Longmaxi shale in the Upper Yangtze Platform, South China," Interpretation, vol. 5, no. 3, pp. T437T449, 2017.

[16] Y. T. Chen, S. Jiang, D. X. Zhang, and C. Y. Liu, "An adsorbed gas estimation model for shale gas reservoirs via statistical learning," Applied Energy, vol. 197, pp. 327-341, 2017.

[17] J. Q. Tan, P. Weniger, B. Krooss et al., "Shale gas potential of the major marine shale formations in the Upper Yangtze Platform, South China, part II: methane sorption capacity," Fuel, vol. 129, pp. 204-218, 2014.

[18] T. W. Zhang, G. S. Ellis, S. C. Ruppel, K. Milliken, and R. S. Yang, "Effect of organic-matter type and thermal maturity on methane adsorption in shale-gas systems," Organic Geochemistry, vol. 47, pp. 120-131, 2012.

[19] J. B. Curtis, "Fractured shale-gas systems," AAPG Bulletin, vol. 86, no. 11, pp. 1921-1938, 2002.

[20] W. H. Song, B. W. Yao, J. Yao et al., "Methane surface diffusion capacity in carbon-based capillary with application to organicrich shale gas reservoir," Chemical Engineering Journal, vol. 352, pp. 644-654, 2018.

[21] M. Gasparik, P. Bertier, Y. Gensterblum, A. Ghanizadeh, B. M. Krooss, and R. Littke, "Geological controls on the methane storage capacity in organic-rich shales," International Journal of Coal Geology, vol. 123, pp. 34-51, 2014. 
[22] J. Kim, D. Kim, W. Lee, Y. Lee, and H. Kim, "Impact of total organic carbon and specific surface area on the adsorption capacity in Horn River shale," Journal of Petroleum Science and Engineering, vol. 149, pp. 331-339, 2017.

[23] J. J. Li, X. T. Yan, W. M. Wang et al., "Key factors controlling the gas adsorption capacity of shale: a study based on parallel experiments," Applied Geochemistry, vol. 58, pp. 88-96, 2015.

[24] G. R. L. Chalmers and R. M. Bustin, "The organic matter distribution and methane capacity of the Lower Cretaceous strata of Northeastern British Columbia, Canada," International Journal of Coal Geology, vol. 70, no. 1-3, pp. 223-239, 2007.

[25] G. R. L. Chalmers and R. M. Bustin, "Lower Cretaceous gas shales in northeastern British Columbia, part I: geological controls on methane sorption capacity," Bulletin of Canadian Petroleum Geology, vol. 56, no. 1, pp. 1-21, 2008.

[26] R. Littke, B. Krooss, E. Idiz, and J. Frielingsdorf, “95/05715 Molecular nitrogen in natural gas accumulations: generation from sedimentary organic matter at high temperatures," Fuel and Energy Abstracts, vol. 36, no. 6, pp. 409-430, 1995.

[27] C. Liu, "Present conditions and prospect of shale gas development," Oil Forum, vol. 3, pp. 32-37, 2013.

[28] X. Tang, N. Ripepi, N. P. Stadie, and L. J. Yu, "Thermodynamic analysis of high pressure methane adsorption in Longmaxi shale," Fuel, vol. 193, pp. 411-418, 2017.

[29] J. Li, S. X. Zhou, G. Gaus et al., "Characterization of methane adsorption on shale and isolated kerogen from the Sichuan Basin under pressure up to $60 \mathrm{MPa}$ : Experimental results and geological implications," International Journal of Coal Geology, vol. 189, pp. 83-93, 2018.

[30] D. J. K. Ross and R. M. Bustin, "Shale gas potential of the Lower Jurassic Gordondale Member, northeastern British Columbia, Canada," Bulletin of Canadian Petroleum Geology, vol. 55, no. 1, pp. 51-75, 2007.

[31] J. Zou, R. Rezaee, Q. Xie, L. J. You, K. Q. Liu, and A. Saeedi, "Investigation of moisture effect on methane adsorption capacity of shale samples," Fuel, vol. 232, pp. 323-332, 2018.

[32] J. Zou, R. Rezaee, and Y. J. Yuan, "Investigation on the adsorption kinetics and diffusion of methane in shale samples," Journal of Petroleum Science and Engineering, vol. 171, pp. 951-958, 2018.

[33] X. F. Li, Y. C. Pu, C. Y. Sun et al., "Recognition of absorption/desorption theory in coalbed methane reservoir and shale gas reservoir," Acta Petrolei Sinica, vol. 35, no. 6, pp. 1113-1129, 2014.

[34] H. C. Helgeson, L. Richard, W. F. McKenzie, D. L. Norton, and A. Schmitt, "A chemical and thermodynamic model of oil generation in hydrocarbon source rocks," Geochimica et Cosmochimica Acta, vol. 73, no. 3, pp. 594-695, 2009.

[35] J. Seewald, B. C. Benitez-Nelson, and J. K. Whelan, "Laboratory and theoretical constraints on the generation and composition of natural gas," Geochimica Et Cosmochimica Acta, vol. 53, no. 3, pp. 653-661, 2010.

[36] M. Yanan, L. Xiangfang, J. Lee et al., "Characterization of hydrocarbon/pores generation and methane adsorption in shale organic matter," Petroleum Science and Technology, vol. 36, no. 15, pp. 1187-1193, 2018.

[37] S. Yan, Z. Xinmin, and L. Shaobo, The Basic Theory of Geology and Development of CBM in China, Science Press, 2012.

[38] J. A. Gutierrez-Rodriguez, R. J. Purcell, and F. E. Aplan, "Estimating the hydrophobicity of coal," Colloids and Surfaces, vol. 12, pp. 1-25, 1984.
[39] E. Kellner and J. M. Waddington, "Dynamics of biogenic gas bubbles in peat: potential effects on water storage and peat deformation," Water Resources Research, vol. 41, no. 8, 2005.

[40] Z. Suian, "Views on types of desorption effect in the process of CBM production," China Coalbed Methane, vol. 1, no. 1, pp. 26-28, 2004. 